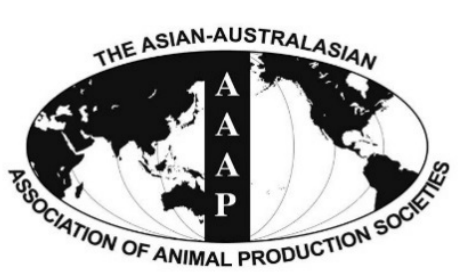

\title{
Effects of Gestational Housing on Reproductive Performance and Behavior of Sows with Different Backfat Thickness
}

\author{
K. H. Kim, A. Hosseindoust, S. L. Ingale, S. H. Lee, H. S. Noh, Y. H. Choi, \\ S. M. Jeon, Y. H. Kim ${ }^{1}$, and B. J. Chae* \\ Department of Animal Resources Science, College of Animal Life Sciences, \\ Kangwon National University, Chuncheon 200-701, Korea
}

\begin{abstract}
The present study investigated the effects of back-fat thickness at d 107 of gestation and housing types during gestation on reproductive performance and behavior of sows. A total of 64 crossbred sows (Landrace $\times$ Yorkshire) in their 3 to 4 parities were allotted to one of four treatments $(\mathrm{n}=16)$ over two consecutive parities. During each parity, sows were assigned to two gestational housing types (stall or group housing) and two level of back-fat thickness $(<20$ or $\geq 20)$ at $d 107$ of gestation. Gestating sows were transferred from gestational crates to stalls or pens (group housing) 5 weeks before farrowing. All sows were moved to farrowing crates on $\mathrm{d} 109$ of gestation. At weaning, back-fat thickness changes were lesser $(\mathrm{p}<0.05)$ in sows having back-fat thickness $<20 \mathrm{~mm}$ than that of sows with $\geq 20 \mathrm{~mm}$ back-fat thickness at $107 \mathrm{~d}$ of gestation. Group housed sows had greater $(\mathrm{p}<0.05)$ feed intake and shorter $(\mathrm{p}<0.05)$ weaning-to-estrus interval than that of sows in stalls. At weaning, back-fat thickness changes were lesser $(p<0.05)$ in group housed sows than that of sows in stalls. The number of piglets at weaning, growth rate and average daily gain were greater $(p<0.05)$ in group housed sows than that of sows in stalls. During gestation, walking duration was more $(\mathrm{p}<0.05)$ in group housed sows. Group housed sows had lesser $(p<0.05)$ farrowing duration and greater $(p<0.05)$ eating time than that of sows in stalls. Result obtained in present study indicated that sows with $\geq 20 \mathrm{~mm}$ back-fat thickness at 107 days had better reproductive performance. Additionally, group housing of sows during last five week of gestation improved the performance and behavior and reproductive efficiency of sows. (Key Words: Back-fat Thickness, Behavior, Housing, Reproductive Performance, Sows)
\end{abstract}

\section{INTRODUCTION}

In modern pig industry maintaining optimal body condition of high producing sows has become an issue of considerable importance due to the economic pressure to achieve best production targets (Whittemore, 1996; Maes et al., 2004). The measurement of backfat thickness of sows constitutes a more objective and precise method to assess the body condition of sows (Charette et al., 1996). During the last phase of gestation and lactation the sows feed intake is not sufficient to meet the nutrient requirements for

\footnotetext{
* Corresponding Author: B. J. Chae. Tel: +82-33-250-8616, Fax: +82-33-244-4946, E-mail: bjchae@kangwon.ac.kr

${ }^{1}$ Department of Animal Resources Development, Swine Science Division, National Institute of Animal Science, RDA, Cheonan, 31000 , Korea.

Submitted Dec. 30, 2014; Revised Feb. 3, 2015; Accepted Sept. 1, 2015
}

maintenance, fetal growth and lactation, which leads to mobilization of reserve protein and backfat (Aherne et al., 1999). It has been reported that excessive loss of body protein and backfat during gestation and lactation is associated with an increased percentage of stillborn piglets (Maes et al., 2004), reduced litter size, litter growth (McKay, 1993) and prolonged weaning to estrus interval (De Rensis et al., 2005; Serenius et al., 2006). On the other hand, excess body fat at the end of gestation leads to farrowing difficulties and more stillborn piglets (Zaleski and Hacker, 1993), postpartum dysgalactia and higher culling rate due to locomotion difficulties (Martineau and Klopfenstein 1996; Dourmad et al., 2001). Therefore, backfat thickness should be maintained within an optimal range to ensure the best reproductive performance.

A major public issue for swine industry these days is housing and welfare of sows during gestation. It is 
estimated that $75.8 \%$ of all gestating breeding stock in the US is housed in individual stalls (USDA, Animal and Plant Health Inspection Service, 2014). However, increased consumer awareness about animal welfare issues had led producers to begin the implementation of group housing of sows during gestation. Gestational pens with partial stalls are designed for use with small groups of sows and lend themselves well for units being converted from individual gestational crate into group housing system (Boyle, 2005; Zhao et al., 2013). Previous studies compared group housing to stall housing during gestation periods and reported a varied performance; whether that being a significantly greater result for group housing sows (Bates et al., 2003), no change among the groups (Hemsworth et al., 2013; Zhao et al., 2013) or a greater result for stall housing (Den Hartog et al., 1993). Therefore, understanding the effect of changing from gestational stalls to group housing on the reproductive performance and behavior of sows is essential to implement alternative gestational housing systems and assure the well-being of sows. The objectives of the present study were to investigate the effects of backfat thickness and housing pattern during gestation on reproductive performance and behavior of sows.

\section{MATERIALS AND METHODS}

\section{Animals and management}

The protocol for the present experiment was approved by the Institutional Animal Care and Use Committee of Kangwon National University, Republic of Korea.

A total of 64 crossbred sows (Landrace $\times$ Yorkshire) in their 3 to 4 parities were allotted to one of four treatments $(n=16)$ over two consecutive parities, but 5 sows culled in the second (Fourth parity) experiment meant a total of 59 sows applied for the experiment. All sows used in the present study were artificially inseminated 2 times after onset of estrus, and pregnancy was detected and confirmed at d 30 post breeding using a Pharvision B-mode ultrasound machine (AV 2100V; Ambisea Tech. Corp., Shenzhen, China). During gestation, all sows were housed in individual gestation stalls $(2.20 \times 0.65 \mathrm{~m})$ with fully slatted concrete flooring. Five week before farrowing, sows $(n=32)$ were assigned to two gestational housing types (stalls or group housing) and two level of backfat thickness ( $<20$ or $\geq 20 \mathrm{~mm}$ ) at $\mathrm{d} 107$ of gestation using $2 \times 2$ factorial design. Group housed sows were kept in two pens $(10.4 \times 5.4 \mathrm{~m})$ with 16 sows per pen. All sows were moved to farrowing crates $(2.2 \times 0.65 \mathrm{~m})$ on $\mathrm{d} 109$ of gestation.

Each crate had a single feeder, and water was always available through a nipple drinker. The farrowing room temperature was maintained at $20^{\circ} \mathrm{C}$ before farrowing, increased to $24^{\circ} \mathrm{C}$ for the first 2 week of lactation and subsequently lowered to $20^{\circ} \mathrm{C}$. Heating pads for piglets were located on either side of the farrowing crates and maintained at $36^{\circ} \mathrm{C}$. Piglets were weaned at $21 \mathrm{~d}$ after farrowing. Before the farrowing, they were allocated the same amount of experimental diet $(2.6 \mathrm{~kg} / \mathrm{sow})$ for both group housing and stall sows, once a day at $0900 \mathrm{~h}$. There was one feeder per sow for group housing treatment and each sow could individually occupy one feeder without having the accessibility to the other sows feed. After farrowing, sows had ad libitum access to water via a drinker located in the feed trough in each farrowing crate. The feeders were checked 3 times per day to be refilled when required. All the sows were fed a common corn-soybean meal based diet as per National Research Council (1998) requirements for gestation and lactation (Table 1). The value of average daily gain (ADG) of piglets was calculated by final body weight minus the first body weight divided by weaning date (day) multiplied by the number of weaned piglets.

\section{Backfat measurements and data collection}

Sow backfat thickness at 10th rib, $6.5 \mathrm{~cm}$ from one side of the backbone was measured at d 107 of gestation, after farrowing ( $\mathrm{d} 1$ of lactation), and at weaning (d 21 of lactation) by using an ei-medical imaging ultrasound (Loveland, CO). Changes in backfat thickness of sows during lactation were measured by calculating the difference between backfat thicknesses at d 1 of lactation and backfat thickness at weaning. Standard litter traits like number born and born alive, body weight $(\mathrm{kg})$ at birth, and weaning, growth rate $(\mathrm{kg} / \mathrm{d})$, and ADG (g/piglets) were recorded. Feed intake $(\mathrm{kg} / \mathrm{d})$ of each sows and weaning-toestrus interval (d) were also recorded.

\section{Behavioral measures}

Sow behavior during gestation and lactation were recorded using Geovision GV-1240 video capture combo card (Geovision, Inc., Irvine, CA, USA) and viewed using EZViewlog (Geovision, Inc., USA) in real-time. Behavior was observed and registered continuously for 10 (07001700) $\mathrm{h}$ on $\mathrm{d} 49,77$, and 104 of gestation and during farrowing. Behaviors registered included: ventral lying, lateral lying, sitting, standing, walking, drinking, eating, and farrowing duration.

\section{Statistical analyses}

Data generated in the present experiment was analyzed as a $2 \times 2$ factorial arrangement in a completely randomized design. Data were replicated over time, whereas the housing type and back fat thickness were the fixed effect. Sow was considered the experimental unit. The main effects of housing type, backfat thickness at $107 \mathrm{~d}$ of gestation, and their interaction were determined by mixed procedure of SAS statistical program (SAS Inst., Inc., Cary, NC, USA). A 
Table 1. Ingredient and chemical composition of experimental diets (as-fed basis)

\begin{tabular}{|c|c|c|}
\hline Item & $\begin{array}{c}\text { Gestation } \\
\text { diet }\end{array}$ & $\begin{array}{c}\text { Lactation } \\
\text { diet }\end{array}$ \\
\hline \multicolumn{3}{|l|}{ Ingredients (\%) } \\
\hline Corn & 41.45 & 40.95 \\
\hline Wheat & 12.00 & 10.00 \\
\hline Wheat bran & 4.00 & - \\
\hline Palm kennel meal & 4.00 & 2.00 \\
\hline Distiller's dried grains with solubles & 12.00 & 8.00 \\
\hline Rapeseed meal & 3.00 & - \\
\hline Soybean meal (Local) & 6.95 & 22.83 \\
\hline Soybean meal (Import) & - & 5.88 \\
\hline Coconut meal & 4.00 & - \\
\hline Corn gluten feed & 2.00 & - \\
\hline Animal fat & 5.21 & 4.03 \\
\hline Molasses & 2.00 & 3.00 \\
\hline L-Lysine $\cdot \mathrm{HCl}(78 \%)$ & 0.08 & 0.14 \\
\hline DL-Methionine (88\%) & - & 0.04 \\
\hline Choline chloride (50\%) & 0.06 & 0.06 \\
\hline Limestone & 1.47 & 1.38 \\
\hline Mono dicalcium phosphate & 0.85 & 0.85 \\
\hline Salt & 0.55 & 0.50 \\
\hline Vitamin premix $^{1}$ & 0.20 & 0.16 \\
\hline Mineral premix ${ }^{2}$ & 0.10 & 0.10 \\
\hline Phytase $^{3}$ & 0.03 & 0.03 \\
\hline Mannanase $^{4}$ & 0.05 & 0.05 \\
\hline Total & 100.00 & 100.00 \\
\hline \multicolumn{3}{|l|}{ Calculated composition $(\%)$} \\
\hline $\mathrm{ME}(\mathrm{kcal} / \mathrm{kg})$ & 3,265 & 3,350 \\
\hline $\mathrm{CP}$ & 14.58 & 20.13 \\
\hline $\mathrm{Ca}$ & 0.75 & 0.75 \\
\hline Avg. P & 0.32 & 0.32 \\
\hline Lys $(\%)$ & 0.65 & 1.15 \\
\hline Met+Cys (\%) & 0.56 & 0.72 \\
\hline
\end{tabular}

ME, metabolizable energy; $\mathrm{CP}$, crude protein.

${ }^{1}$ Supplied per kg diet: 9,600 IU vitamin A, 1,800 IU vitamin $D_{3}, 24 \mathrm{mg}$ vitamin $\mathrm{E}, 1.5 \mathrm{mg}$ vitamin $\mathrm{B}_{1}, 12 \mathrm{mg}$ vitamin $\mathrm{B}_{2}, 2.4 \mathrm{mg}$ vitamin $\mathrm{B}_{6}$, $0.045 \mathrm{mg}$ vitamin $\mathrm{B}_{12}, 1.5 \mathrm{mg}$ vitamin $\mathrm{K}_{3}, 24 \mathrm{mg}$ pantothenic acid, $45 \mathrm{mg}$ niacin, $0.09 \mathrm{mg}$ biotin, $0.39 \mathrm{mg}$ folic acid, $7.2 \mathrm{mg}$ ethoxyquin.

${ }^{2}$ Supplied per kg diet: $150 \mathrm{mg} \mathrm{Fe}\left(\mathrm{FeSO}_{4}\right), 96 \mathrm{mg} \mathrm{Cu}\left(\mathrm{CuSO}_{4} ; \mathrm{H}_{2} \mathrm{O}\right), 72$ $\mathrm{mg} \mathrm{Zn}\left(\mathrm{ZnSO}_{4}\right), 46.5 \mathrm{mg} \mathrm{Mn}\left(\mathrm{MnO}_{2}\right), 0.9 \mathrm{mg} \mathrm{I}\left(\mathrm{Ca}(\mathrm{IO})_{3}\right), 0.3 \mathrm{mg} \mathrm{Se}$ $\left(\mathrm{Na}_{2} \mathrm{SeO}_{3}\right)$.

${ }^{3}$ Provided 300 FTU/kg of diet phytase (Phyzyme XP 10000, Danisco Animal Nutrition, Marlborough Wiltshire, UK).

4 Provided 120 FTU/kg $\beta$-mannanase (Hemicell, ChemGen Corp., Gaithersburg, MD, USA)

p-values $\leq 0.05$ were considered statistically significant.

The data were tested for main effects of housing, back fat, and their possible interaction. The following model statement was used:

$$
\mathrm{Y}_{\mathrm{ijt}}=\mu+\alpha_{\mathrm{i}}+\beta_{\mathrm{j}}+\gamma_{\mathrm{t}}+\alpha \beta_{\mathrm{ij}}+\varepsilon_{\mathrm{ijt}}
$$

where $Y_{\mathrm{ijt}}=$ measured response, $\mu=$ overall mean, $\alpha_{\mathrm{i}}=$ housing effect, $\beta_{\mathrm{j}}=$ back fat effect, $\gamma_{\mathrm{t}}=$ the fixed time effect when the measurement was taken, $\alpha \beta_{\mathrm{ij}}=$ interaction between housing and back fat effect, and $\varepsilon_{\mathrm{ijt}}=$ residual error.

\section{RESULTS}

\section{Backfat thickness, feed intake and weaning-to-estrus interval}

The backfat thickness, feed intake, and weaning-toestrus interval of sows are presented in Table 2. At weaning, group housed sows had greater $(\mathrm{p}<0.01)$ backfat thickness than that of sows in gestation stalls. Changes in backfat thickness during lactation were lesser $(\mathrm{p}<0.05)$ in group housed sows than that of sows in gestation stalls. Group housed sows had greater $(\mathrm{p}<0.05)$ feed intake and shorter $(p<0.05)$ weaning-to-estrus interval than that of sows in gestation stalls. Sows backfat thickness at $107 \mathrm{~d}$ of gestation had no effects $(p>0.05)$ on feed intake and weaning-to-estrus interval $(\mathrm{p}>0.05)$. There was no housing type $\times$ backfat thickness interaction for any of the measured variables.

\section{Litter performances}

The effect of housing type and backfat thickness of sows at $\mathrm{d} 107$ of gestation on litter performances are shown in Table 3. There were no effects $(p>0.05)$ of housing pattern and backfat thickness at $\mathrm{d} 107$ of gestation on numbers of total born and born alive and body weight of live piglets at birth. Numbers of piglets at weaning, growth rate, and ADG were greater $(\mathrm{p}<0.05)$ in group housed sows than that of sows housed in gestation stalls. Moreover, body weight of piglets at weaning, growth rate, and number of weaned piglets were greater $(p<0.05)$ in sows with $\geq 20 \mathrm{~mm}$ backfat thickness than that of sows with $<20 \mathrm{~mm}$ backfat thickness at $107 \mathrm{~d}$ of gestation.

\section{Behavioral patterns}

Behavioral patterns of sows during gestation and lactation are presented in Table 4 and 5. During gestation, housing type and backfat thickness at $\mathrm{d} 107$ of gestation had no effects $(p>0.05)$ on ventral lying, sitting, standing and drinking. Walking was significantly increased $(p<0.05)$ in group housed sows than that of sows in gestation stalls. During farrowing, housing type and backfat thickness at $\mathrm{d}$ 107 of gestation had no effects ( $>0.05$ ) on ventral lying, lateral lying, sitting, standing, and drinking. However, eating duration was significantly greater $(p<0.05)$ in group housed sows than that of sows in gestation stalls. There was no housing type $\times$ backfat thickness interaction for any of the measured variables.

\section{DISCUSSION}

Effects of backfat thickness on reproductive performance 
Table 2. Effects of gestational housing and different backfat thickness on backfat thickness changes, feed intake and weaning to estrus interval in sows during two consecutive parities

\begin{tabular}{|c|c|c|c|c|c|c|c|c|c|c|c|c|}
\hline \multirow{3}{*}{$\begin{array}{l}\text { Housing type } \\
\text { Backfat thickness (mm) }\end{array}$} & \multicolumn{4}{|c|}{ Parity 3} & \multicolumn{4}{|c|}{ Parity 4} & \multirow{3}{*}{ SEM } & \multicolumn{3}{|c|}{ p-value ${ }^{1}$} \\
\hline & \multicolumn{2}{|c|}{ Stall } & \multicolumn{2}{|c|}{ Group housing } & \multicolumn{2}{|c|}{ Stall } & \multicolumn{2}{|c|}{ Group housing } & & \multirow[t]{2}{*}{$\mathrm{H}$} & \multirow[t]{3}{*}{$\mathrm{B}$} & \multirow[t]{3}{*}{$\mathrm{H} \times \mathrm{B}$} \\
\hline & $<20$ & $\geq 20$ & $<20$ & $\geq 20$ & $<20$ & $\geq 20$ & $<20$ & $\geq 20$ & & & & \\
\hline & \multicolumn{2}{|c|}{$(\mathrm{n}=16)(\mathrm{n}=16)$} & \multicolumn{2}{|c|}{$(\mathrm{n}=16)(\mathrm{n}=16)$} & \multicolumn{2}{|c|}{$(\mathrm{n}=15)(\mathrm{n}=14)$} & $(\mathrm{n}=15)$ & $(\mathrm{n}=15)$ & & & & \\
\hline \multicolumn{13}{|l|}{ Backfat thickness (mm) } \\
\hline d 1 of lactation (A) & 19.51 & 21.50 & 19.61 & 21.49 & 19.53 & 21.52 & 19.61 & 21.54 & 0.31 & 0.03 & 0.60 & 0.65 \\
\hline d 21 of lactation (B) & 15.54 & 16.29 & 17.00 & 17.64 & 16.51 & 17.31 & 17.94 & 18.23 & 0.22 & 0.05 & 0.87 & 0.79 \\
\hline Change $(\mathrm{A}-\mathrm{B})$ & -3.97 & -5.21 & -2.61 & -3.85 & -3.02 & -4.21 & -2.67 & -3.31 & 0.12 & 0.04 & 0.02 & 0.06 \\
\hline Feed intake $(\mathrm{kg} / \mathrm{d})$ & 6.02 & 6.29 & 7.11 & 7.08 & 6.38 & 6.21 & 7.23 & 7.14 & 0.21 & 0.04 & 0.43 & 0.67 \\
\hline Wean-to-estrus (d) & 4.46 & 4.68 & 4.29 & 4.28 & 4.49 & 4.50 & 4.17 & 4.20 & 0.11 & 0.04 & 0.28 & 0.35 \\
\hline
\end{tabular}

SEM, standard error of the mean.

${ }^{1} \mathrm{H}$, main effect of housing type (stall vs group housing); $\mathrm{B}$, main effect of backfat thickness $(<20$ vs $\geq 20$ ); $\mathrm{H} \times \mathrm{B}=$ housing type $\times$ backfat thickness interaction.

\section{of sows}

It is well established that, maintaining backfat thickness and body conditions of sows during last third of gestation and early lactation are crucial to determine subsequent reproductive performance of sows (Houde et al., 2010). Variation in feed intake, feeding pattern, and milk production between sows during lactation is likely responsible for variation in backfat thickness and losses of backfat levels at weaning (Maes et al., 2004). In the present study, there were no effects of backfat thickness at $107 \mathrm{~d}$ of gestation on feed intake of sows during lactation, but backfat losses during lactation were lesser in sows with $<20$ $\mathrm{mm}$ backfat thickness than sows with $\geq 20 \mathrm{~mm}$. It has been reported that the level of backfat losses were proportional to numbers of live piglet weaned (Maes et al., 2004). On the other hand, sows with lower backfat thickness wean fewer piglets per litter (McKay, 1993). Greater backfat losses in sows with $\geq 20 \mathrm{~mm}$ backfat in the present study might be due to greater numbers and growth rate of weaned piglets than that of sows with $<20 \mathrm{~mm}$ backfat thickness.

The group housed sows showed a greater weaned number, growth rate and ADG for piglets compared with the stall sows. It has been shown that group housing can positively affect the reproductive performance of sows (Weng et al., 2009a). They concluded that the group housing decreased the number of stillborn piglets and also increased the live litter weight at $14 \mathrm{~d}$ and $28 \mathrm{~d}$ after parturition compared with stalled sows. In this study body weight, growth rate and numbers weaned of piglets at weaning were greater in sows with $\geq 20 \mathrm{~mm}$ backfat thickness than that of sows with $<20 \mathrm{~mm}$ backfat thickness. Our results are in contrast with Whittemore et al. (1995), who observed that sows with greater backfat thickness achieved higher litter size and greater litter performance than that of sows with lower backfat thickness. On the other hand, Maes et al. (2004) observed negative association between the backfat thickness and the litter size at weaning. Previously it has been reported that excessive backfat at the end of gestation leads to reproductive performance disorders like difficulties in farrowing, more stillborn piglets (Zaleski and Hacker, 1993), post-partum dyslactia, locomotion difficulties and higher culling rate (Martineau

Table 3. Effects of gestational housing and backfat thickness on litter size and piglet performance during two consecutive parities

\begin{tabular}{|c|c|c|c|c|c|c|c|c|c|c|c|c|}
\hline \multirow{3}{*}{$\begin{array}{l}\text { Housing type } \\
\text { Backfat thickness (mm) }\end{array}$} & \multicolumn{4}{|c|}{ Parity 3} & \multicolumn{4}{|c|}{ Parity 4} & \multirow{3}{*}{ SEM } & \multicolumn{3}{|c|}{ p-value ${ }^{1}$} \\
\hline & \multicolumn{2}{|c|}{ Stall } & \multicolumn{2}{|c|}{ Group housing } & \multicolumn{2}{|c|}{ Stall } & \multicolumn{2}{|c|}{ Group housing } & & \multirow[t]{2}{*}{$\mathrm{H}$} & \multirow[t]{2}{*}{ B } & \multirow[t]{2}{*}{$\mathrm{H} \times \mathrm{B}$} \\
\hline & $<20$ & $\geq 20$ & $<20$ & $\geq 20$ & $<20$ & $\geq 20$ & $<20$ & $\geq 20$ & & & & \\
\hline & \multicolumn{2}{|c|}{$(\mathrm{n}=16)(\mathrm{n}=16)$} & \multicolumn{2}{|c|}{$(\mathrm{n}=16)(\mathrm{n}=16)$} & \multicolumn{4}{|c|}{$(\mathrm{n}=15)(\mathrm{n}=14) \quad(\mathrm{n}=15) \quad(\mathrm{n}=15)$} & & & & \\
\hline \multicolumn{13}{|l|}{ Piglet performance } \\
\hline Numbers of total born ${ }^{2}$ & 11.21 & 11.49 & 11.32 & 11.25 & 11.55 & 11.83 & 11.66 & 11.59 & 0.18 & 0.19 & 0.93 & 0.70 \\
\hline Numbers of born alive ${ }^{2}$ & 9.63 & 9.87 & 9.96 & 10.19 & 9.93 & 10.17 & 10.26 & 10.50 & 0.23 & 0.73 & 0.77 & 0.80 \\
\hline BW of born alive (kg) & 12.07 & 12.36 & 12.07 & 12.52 & 12.42 & 12.73 & 12.44 & 12.89 & 0.19 & 0.40 & 0.30 & 0.43 \\
\hline Numbers weaned $^{2}$ & 9.35 & 9.57 & 9.76 & 9.78 & 9.33 & 9.46 & 9.96 & 10.06 & 0.21 & 0.03 & 0.02 & 0.06 \\
\hline BW at weaning $(\mathrm{kg})$ & 57.49 & 58.90 & 64.61 & 65.98 & 59.20 & 60.66 & 66.55 & 67.96 & 2.41 & 0.13 & 0.03 & 0.15 \\
\hline Growth rate $(\mathrm{kg} / \mathrm{d})$ & 2.16 & 2.24 & 2.49 & 2.55 & 2.25 & 2.28 & 2.56 & 2.60 & 0.12 & 0.01 & 0.03 & 0.07 \\
\hline ADG (g/piglet) & 231 & 233 & 257 & 261 & 237 & 241 & 258 & 262 & 7.49 & 0.04 & 0.167 & 0.12 \\
\hline
\end{tabular}

SEM, standard error of the mean; BW, body weight; ADG, average daily gain.

${ }^{1} \mathrm{H}$, main effect of housing type (stall vs group housing); B, main effect of backfat thickness $(<20$ vs $\geq 20$ ); H $\times \mathrm{B}=$ housing type $\times$ backfat thickness interaction.

${ }^{2}$ Piglets/litter. 
Table 4. Effects of gestational housing and different backfat thickness on behavioral patterns of gestating sows during two consecutive parities

\begin{tabular}{|c|c|c|c|c|c|c|c|c|c|c|c|c|}
\hline \multirow{3}{*}{$\begin{array}{l}\text { Housing type } \\
\text { Backfat thickness (mm) }\end{array}$} & \multicolumn{4}{|c|}{ Parity 3} & \multicolumn{4}{|c|}{ Parity 4} & \multirow{4}{*}{ SEM } & \multicolumn{3}{|c|}{ p-value ${ }^{1}$} \\
\hline & \multicolumn{2}{|c|}{ Stall } & \multicolumn{2}{|c|}{ Group housing } & \multicolumn{2}{|c|}{ Stall } & \multicolumn{2}{|c|}{ Group housing } & & \multirow[t]{3}{*}{$\mathrm{H}$} & \multirow[t]{3}{*}{ B } & \multirow[t]{3}{*}{$\mathrm{H} \times \mathrm{B}$} \\
\hline & $<20$ & $\geq 20$ & $<20$ & $\geq 20$ & $<20$ & $\geq 20$ & $<20$ & $\geq 20$ & & & & \\
\hline & $(n=16)$ & $(n=16)$ & $(\mathrm{n}=16)$ & $(n=16)$ & $(\mathrm{n}=15)$ & $(n=14)$ & $(n=15$ & $(n=15)$ & & & & \\
\hline \multicolumn{13}{|l|}{ Behavior (\%) } \\
\hline Ventral lying & 64.69 & 64.56 & 62.39 & 60.84 & 65.17 & 65.40 & 62.28 & 58.53 & 5.88 & 0.55 & 0.26 & 0.48 \\
\hline Lateral lying & 20.08 & 20.59 & 18.38 & 18.49 & 21.05 & 21.58 & 19.52 & 18.77 & 4.41 & 0.57 & 0.58 & 0.68 \\
\hline Sitting & 9.98 & 10.57 & 9.50 & 9.79 & 7.57 & 7.81 & 8.38 & 8.78 & 0.53 & 0.68 & 0.53 & 0.64 \\
\hline Standing & 3.01 & 2.64 & 3.14 & 3.26 & 4.24 & 3.48 & 1.51 & 5.09 & 0.57 & 0.34 & 0.89 & 0.69 \\
\hline Walking & 0.00 & 0.00 & 5.17 & 5.82 & 0.00 & 0.00 & 6.67 & 6.97 & 0.60 & 0.01 & 0.74 & 0.42 \\
\hline Drinking & 2.24 & 1.65 & 1.41 & 1.80 & 1.98 & 1.74 & 1.63 & 1.87 & 0.49 & 0.97 & 0.40 & 0.86 \\
\hline
\end{tabular}

SEM, standard error of the mean

${ }^{1} \mathrm{H}$, main effect of housing type (stall vs group housing); B, main effect of backfat thickness $(<20$ vs $\geq 20)$; $\mathrm{H} \times \mathrm{B}=\mathrm{housing}$ type $\times$ backfat thickness interaction.

and Klopfenstein, 1996; Dourmad et al., 2001). These observations indicate that too low or too high backfat thickness has adverse effect on the reproductive efficiencies of sows. Therefore maintaining moderate backfat thickness throughout reproductive cycle of sows is important for obtaining greater reproductive efficiency.

\section{Effects of housing type on reproductive performance of sows}

Increased consumer awareness about animal welfare issues has led producers to begin the implementation of group housing of sows during gestation. Group housing of sows during gestation resulted in increased exercise, greater control over environment, opportunity for normal social interactions and opportunities to root or manipulate materials (Von Borrell et al., 1997). In the present study, gestating sows were transferred from breeding crates to free gestation stalls or group housing 5 weeks before farrowing and moved to farrowing rooms on d 109 of gestation. The present results indicated that there were no differences for the litter size and litter weight at birth among group housed and stall fed sows. Our results are in agreement with Zhao et al. (2013), who reported that group housed sows had a similar litter size and litter weight at birth to sow in gestational stalls. Similarly, it has been reported that there were no differences in total number of piglets born and born alive per litter for sows housed in pens or gestation stalls (Bates et al., 2003). In contrast, Den Hartog et al. (1993) reported that number of born alive was lower in group housed sows than that of sows in gestation stalls.

In this study, weaning-to-estrus interval was lesser in group housed sows than that of sows kept in gestation stalls. Our results are consistent with Hemsworth (1982), who reported that the weaning-to-estrus interval of group housed sows was lesser than that of sows in stalls. Bates et al. (2003) observed improved return to estrus and farrow rate of group housed sows than that of sows housed individually in stalls. In contrast to Hemsworth (1982) and present

Table 5. Effects of gestational housing and different backfat thickness on behavioral patterns of sows at farrowing during two consecutive parities

\begin{tabular}{|c|c|c|c|c|c|c|c|c|c|c|c|c|}
\hline \multirow{3}{*}{$\begin{array}{l}\text { Housing type } \\
\text { Backfat thickness (mm) }\end{array}$} & \multicolumn{4}{|c|}{ Parity 3} & \multicolumn{4}{|c|}{ Parity 4} & \multirow{4}{*}{ SEM } & \multicolumn{3}{|c|}{ p-value ${ }^{1}$} \\
\hline & \multicolumn{2}{|c|}{ Stall } & \multicolumn{2}{|c|}{ Group housing } & \multicolumn{2}{|c|}{ Stall } & \multicolumn{2}{|c|}{ Group housing } & & \multirow[t]{3}{*}{$\mathrm{H}$} & \multirow[t]{3}{*}{ B } & \multirow[t]{3}{*}{$\mathrm{H} \times \mathrm{B}$} \\
\hline & $<20$ & $\geq 20$ & $<20$ & $\geq 20$ & $<20$ & $\geq 20$ & $<20$ & $\geq 20$ & & & & \\
\hline & $(n=16)$ & $(\mathrm{n}=16)$ & $(\mathrm{n}=16)$ & $(n=16)$ & $(\mathrm{n}=15)$ & $(n=14)$ & $(\mathrm{n}=15)$ & $(n=15)$ & & & & \\
\hline \multicolumn{13}{|l|}{ Behavior (\%) } \\
\hline Ventral lying & 63.19 & 62.44 & 59.35 & 57.82 & 62.75 & 61.99 & 60.05 & 58.33 & 8.93 & 0.98 & 0.39 & 0.54 \\
\hline Lateral lying & 19.09 & 19.48 & 18.43 & 20.25 & 19.46 & 19.86 & 18.47 & 17.45 & 3.44 & 0.90 & 0.47 & 0.65 \\
\hline Sitting & 8.14 & 8.30 & 10.84 & 9.70 & 9.49 & 9.69 & 10.64 & 10.79 & 2.94 & 0.40 & 0.25 & 0.58 \\
\hline Standing & 4.22 & 4.31 & 5.84 & 5.91 & 3.38 & 3.45 & 4.43 & 6.46 & 1.57 & 0.30 & 0.39 & 0.35 \\
\hline Eating & 3.47 & 3.54 & 3.64 & 4.34 & 3.05 & 3.11 & 4.41 & 5.07 & 0.67 & 0.03 & 0.69 & 0.47 \\
\hline Drinking & 1.89 & 1.93 & 1.90 & 1.97 & 1.88 & 1.92 & 1.98 & 1.91 & 0.97 & 0.33 & 0.24 & 0.35 \\
\hline Farrowing duration $(\mathrm{h})$ & 5.53 & 5.65 & 5.11 & 4.44 & 5.30 & 5.41 & 4.84 & 3.45 & 0.46 & 0.05 & 0.17 & 0.15 \\
\hline
\end{tabular}

SEM, standard error of the mean.

${ }^{1} \mathrm{H}$, main effect of housing type (stall vs group housing); B, main effect of backfat thickness $(<20$ vs $\geq 20$ ); H $\times \mathrm{B}=$ housing type $\times$ backfat thickness interaction. 
results, McGlone et al. (2004) reported lesser weaning-toestrus interval of sows housed in stalls than that of group housed sows. Variations in results might be due to variations in farm management between studies.

In the present study, numbers of piglets weaned, feed intake, growth rate and $\mathrm{ADG}$ of piglets were greater in group housed sows than that of sows kept in gestation stalls. Present results are in agreement with Gunn and Friendship (2003), who observed greater number of litter per sow per year in group housed sows compared to sows in gestation stalls. In contrast, Barbari (2000) reported greater number of weaned piglets among sows housed in gestation stalls compared to those housed in various group housing systems. Bates et al. (2003) observed lower litter weight at weaning among group housed sows than that of sows in gestation stalls. Some of the previous studies reported that the reproductive performance of group housed sows is equal to, or superior to that of sows in stall, in term of backfat, litter size, piglet birth weight, piglet weaning weight and wean to estrus interval (McGlone et al., 2004; Rhodes et al., 2005). Greater overall gain at weaning in group housed sow in the present study might be due to greater number of piglets weaned as compared to sows housed in stalls during gestation.

Sows behavior during gestation, farrowing and lactation serves as an interaction between sows and their environment and it is affected by internal and external factors (Rhodes et al., 2005). In the present study, housing type and backfat thickness at d 107 of gestation had no effects on ventral lying, lateral lying, sitting, standing, and drinking behavior during gestation and lactation. Our results are consistent with Calderon Diaz et al. (2014) observed no effects of gestation housing on locomotory behaviors of sows. Group housed sows in the present study had a longer eating time than sows in stalls. Weng et al. (2009b) observed less lying and moving in stall housing before farrowing, however, during lactation, group sows spent more time standing, moving and eating, less time dog sitting and lateral lying. This might be due to the stress caused by shifting the group of housed sows to the farrowing crates. Loose housed sows during gestation are more stressed by confinement in farrowing crates than sows housed in stall during gestation (Boyle et al., 2000). Rhodes et al. (2005) reported that sows show different behavior when housed in gestation stalls, compared with some group pens, because of restricted movement, reduced caloric consumption, reduced opportunities to forage, absence of bedding and restricted social interaction.

\section{CONCLUSIONS}

Result obtained in the present study indicated that sows with $\geq 20 \mathrm{~mm}$ backfat thickness at 107 days of gestation had greater reproductive performance. Additionally, group housing of sows during last five week of gestation improved the reproductive efficiency and behavior of sows.

\section{CONFLICT OF INTEREST}

We certify that there is no conflict of interest with any financial organization regarding the material discussed in the manuscript.

\section{ACKNOWLEDGMENTS}

This work was carried out with the support of Cooperative Research Program for Agriculture Science and Technology Development (Project No. 01160302), Rural Development Administration, Republic of Korea. The authors are thankful to the Institute of Animal Resources, Kangwon National University, Chuncheon, Republic of Korea for providing the technical facilities to conduct this experiment.

\section{REFERENCES}

Aherne, F., G. Foxcroft, and J. E. Pettigrew. 1999. Nutrition of the sow. In: Diseases of Swine. 8th edn (Eds. B. E. Straw, S. D'Allaire, W. L. Mengeling, and D. J. Taylor). Iowa State University Press, Ames, IA, USA. pp. 1029-1043.

Barbari, M. 2000. Analysis of reproductive performance of sows in relation to housing systems. In: ASAE proceedings, 1st International Conference on Swine Housing. Des Moines, IA, USA. pp. 188-196.

Bates, R. O., D. B. Edwards, and R. L. Korthals. 2003. Sow performance when housed either in groups with electronic sow feeders or stalls. Livest. Prod. Sci. 79:29-35.

Boyle, L. A. 2005. Reducing aggression in group housed Sows. In: Proceedings of the Teagasc Pig Farmers Conferences Pages, Teagasc Oakpark, Carlow, Ireland. pp. 10-18.

Boyle, L. A., F. C. Leonard, P. B. Lynch, and P. Brophy. 2000. Influence of housing systems during gestation on the behavior and welfare of gilts in farrowing crates. Anim. Sci. 71:561-570.

Calderon Diaz, J. A., A. G. Fahey, and L. A. Boyel. 2014. Effects of gestation housing system and floor type during lactation on locomotory ability; body, lim, and clow legions; and lyingdown behavior of lactating sows. J. Anim. Sci. 92:1675-1683.

Charette, R., M. Bigras-Poulin, and G. Martineau. 1996. Body condition evaluation in sows. Livest. Prod. Sci. 46:107-115.

De Rensis, F., M. Gherpelli, P. Superchi, and R. N. Kirkwood. 2005. Relationships between backfat depth and plasma leptin during lactation and sow reproductive performance after weaning. Anim. Reprod. Sci. 90:95-100.

Den Hartog, L. A., G. B. C. Backus, and H. M. Vermeer. 1993. Evaluation of housing systems for sows. J. Anim. Sci. 71:1339-1344.

Dourmad, J. Y., M. E'tienne, and J. Noblet. 2001. Measuring 
backfat depth in sows to optimize feeding strategy. Prod Anim, 14(1), 41-50. INRA Prod. Anim. 14:41-50.

Gunn, H. and R. Friendship. 2003. Gestation sows housing in Ontario. In: Proceedings of the American Association of Swine Veterinarians, Orlando, USA. pp. 61-65.

Hemsworth, P. H. 1982. Social environment and reproduction. In: Control of Pig Reproduction (Eds. D. J. A. Cole and G. R. Foxcroft), Butterworths, London, UK. pp. 585-601.

Hemsworth, P. H., M. Rice, J. Nash, K. Giri, K. L. Butler, A. J. Tilbrook, and R. S. Morrison. 2013. Effects of group size and floor space allowance on grouped sows: Aggression, stress, skin injuries, and reproductive performance. J. Anim. Sci. 91:4953-4964.

Houde, A. A., S. Me'thot, B. D. Murphy, V. Bordignon, and M. F. Pali. 2010. Relationships between backfat thickness and reproductive efficiency of sows: A two-year trial involving two commercial herds fixing backfat thickness at breeding. Can. J. Anim. Sci. 90:429-436.

Maes, D. G. D., G. P. J. Janssens, P. Delputte, A. Lammertyn, and A. de Kruif. 2004. Back fat measurements in sows from three commercial pig herds: relationship with reproductive efficiency and correlation with visual body condition scores. Livest. Prod. Sci. 91:57-67.

Martineau, G. P. and C. Klopfenstein. 1996. Body building syndromes in sows (BBS) thin sow syndrome, fat sow syndrome, accordeon sow syndrome. French Swine Research Days, January 30 to February 1, 1996. Paris, France. 28:331338

McGlone, J. J., E. H. von Borrell, J. Deen, A. K. Johnson, D. G. Levis, M. Meunier-Salaün, J. Morrow, D. Reeves, J. L. SalakJohnson, and P. L. Sundberg. 2004. Review: Compilation of the scientific literature comparing housing systems for gestating sows and gilts using measures of physiology, behavior, performance, and health. Prof. Anim. Sci. 20:105-117.

McKay, R. M. 1993. Preweaning losses of piglets as a result of index selection for reduced backfat thickness and increased growth rate. Can. J. Anim. Sci. 73:437-442.

National Research Council. 1998. Nutrient Requirements of Swine, 10th edn. National Academy Press, Washington, DC, USA.
Rhodes, R. T., M. C. Appleby, K. Chinn, L. Douglas, L. D. Firkins, K. A. Houpt, C. Irwin, J. J. McGlone, P. Sundberg, L. Tokach, and R. W. Wills. 2005. Task Force Report: A comprehensive review of housing for pregnant sows. J. Am. Vet. Med. Assoc. 227:1580-1590.

Serenius, T., K. J. Stalder, T. J. Baas, J. W. Mabry, R. N. Goodwin, R. K. Johnson, O. W. Robinson, M. Tokach, and R. K. Miller. 2006. National Pork Producers Council Maternal Line National Genetic Evaluation Program: A comparison of sow longevity and trait associations with sow longevity. J. Anim. Sci. 84:2590-2595.

U.S. Department of Agriculture, Animal and Plant Health Inspection Service. 2014. Swine 2012, Part I: Baseline Reference of Swine Health and Management, 2012. National Animal Health Monitoring System. Fort Collins, CO \#663.0814.

Von Borrell, E., D. M. Broom, D. Scermely, A. A. Dijkhuizen, S. Hylkema, S. A. Edwards, P. Jensen, F. Madec, and C. Stamataris. 1997. The welfare of intensively kept pigs. Report of the Scientific Veterinary Committee, European Commission, December 24, 1997. B3.

Weng, R. C., S. A. Edwards, and L. C. Hsia. 2009a. Effect of individual, group or ESF housing in pregnancy and individual or group housing in lactation on the performance of sows and their piglets. Asian Australas. J. Anim. Sci. 22:1328-1333.

Weng, R. C., S. A. Edwards, and L. C. Hsia. 2009b. Effect of individual, group or ESF housing in pregnancy and individual or group housing in lactation on sow behavior. Asian Australas. J. Anim. Sci. 22:1574-1580.

Whittemore, C. T., J. Y. Dourmad, and M. Ettiene. 1995. Reproduction in primiparous sows nutrition and body condition in relation to productivity. 46th EAAP, Praha Czech Republic, 301.

Whittemore, C. T. 1996. Nutrition reproduction interactions in primiparous sow: A review. Livest. Prod. Sci. 46:65-83.

Zaleski, H. M. and R. R. Hacker. 1993. Variables related to the progress of parturition and probability of stillbirth in swine. Can. Vet. J. 34:109-113.

Zhao, Y., W. L. Flowers, A. Saraiva, K. J. Yeum, and S. W. Kim. 2013. Effect of social ranks and gestation housing systems on oxidative stress status, reproductive performance, and immune status of sows. J. Anim. Sci. 91:5848-5858. 